\title{
Mudança tecnológica e estratificação competitiva em um arranjo produtivo do setor ceramista
}

\author{
Sebastião Décio Coimbra de Souza \\ José Arica \\ Universidade Estadual do Norte Fluminense - UENF
}

\begin{abstract}
Resumo
A dinâmica competitiva em arranjos produtivos locais é influenciada, com maior ou menor freqüência, pelo impacto de novas tecnologias que alteram as características específicas do mercado, pressionando as empresas a uma constante reavaliação de suas estratégias, métodos e rotinas organizacionais. No nível microdinâmico, tal dinâmica pode ser captada e verificada através da correlação entre a dotação de recursos e índices de desempenho de cada unidade de uma amostra estratificada do arranjo. Essa abordagem, desenvolvida a partir de conceitos da teoria evolucionária de mudança técnica, foi empregada em um estudo exploratório no Pólo de Cerâmica Vermelha do Norte Fluminense (RJ). Inicialmente foi desenvolvida uma metodologia para se captar a diversidade tecnológica existente entre as empresas do arranjo. A partir de uma amostra representativa dessa diversidade, elaborou-se uma tipologia para identificação e caracterização das unidades em grupos estratificados. Como resultado, apresentamse, a estratificação competitiva para o arranjo, as principais conclusões da pesquisa de campo e algumas considerações sobre a relevância da abordagem proposta.
\end{abstract}

Palavras-chave

Mudança tecnológica, arranjo produtivo local, cerâmica vermelha.

\section{Technological change and competitive stratification in a red ceramic local cluster}

\begin{abstract}
The competitive dynamics in local clusters is influenced for the frequency and impact of new technologies and for the specific characteristics of the market. Such factors press the companies to constant reevaluation of their strategies, methods and organizational routines, leading to a technological stratification process in the local cluster. In the micro-dynamic level, that stratification can be verified through resources endowment and performance indexes of the firms. That approach is based on the evolutionary theory of technical change, which has been adopted in a exploratory research accomplished the North Fluminense red ceramic cluster (North of Rio de Janeiro StateJ to analyze the impact provoked by the process of technological change in the competitive dynamics of that local productive arrangement. Starting from a representative sample of that diversity, a typology was elaborated for identification, characterization and stratification of specific groups on the local arrangement. As result, it is provided the competitive stratification for the arrangement with their respective characteristics, the case conclusions and some relevant final considerations.
\end{abstract}

Technological change; local cluster, red ceramics. 


\section{INTRODUC̄̃̃o}

A mudança tecnológica no âmbito das empresas pode ser entendida como um processo de crescimento, influenciado por fatores endógenos (trajetórias, rotinas organizacionais, estratégias, etc.), bem como pela configuração local dos arranjos onde elas se situam (aglomerados, distritos, setores, blocos, etc.). A dinâmica deste processo envolve busca e adoção de novas tecnologias, exploração, adaptação e imitação (DOSI, 1982). Pressões competitivas de tecnologias novas ou correlatas e desafios ou ideais visionários dos líderes, além das características do ambiente no qual se inserem, contribuem para acelerar o processo de mudança e inovação. Novos estudos, principalmente empíricos, têm procurado refletir este novo ambiente econômico (CHANDLER JR et al., 1999).

Por outro lado, a infra-estrutura e o ambiente regional/ local assumem papel determinante nas novas abordagens do desenvolvimento econômico. Muitos estudos nesse sentido têm tido destaque na literatura (ver, por exemplo, PORTER, 1989, e MALECKI \& ÖINAS, 1998). Entretanto, estes estudos focam quase que apenas em países centrais e exclusivamente em setores industriais altamente avançados, que poderiam ser posicionados no nível mais elevado de uma escala de evolução tecnológica hipotética, cujo fator determinante da competitividade é a inovação.

Como forma de se captar as diversidades internas e a competitividade de segmentos de cadeias e sistemas produtivos locais tem crescido o interesse no enfoque da mesoanálise para o estudo da dinâmica competitiva desses tipos de arranjos, tanto do ponto de vista de pesquisa, como para o direcionamento de políticas públicas e iniciativas de apoio tecnológico à competitividade (KLIEMANN \& HANSEN, 2002; SOUZA \& ARICA, 2006).

Ficam evidentes, entretanto, lacunas entre as abordagens adotadas (baseadas em experiências de ambientes altamente dinâmicos) e os métodos empregados (usados para a análise de ambientes pouco evoluídos tecnologicamente, mas fundamentais para a economia de certas microrregiões periféricas, onde a mudança se dá de maneira lenta e, muitas vezes, somente a partir da contrapartida de fatores exógenos). Nesse sentido, metodologias e abordagens adequadas para a análise de microssistemas produtivos, e a consideração de conceitos nãoestáticos em nível microrregional e/ou mesoeconômico, necessitam ser adaptadas. Por outro lado, não existem metodologias gerais que considerem aspectos dinâmicos evolutivos e, ao mesmo tempo, características locais e setoriais. Desse modo, abordagens próprias têm de ser construídas e as informações necessárias dependem de pesquisa empírica. Conseqüentemente, estudos das relações interfirmas e de segmentos de cadeias produtivas se fazem necessários para que se possibilite a análise dos agentes e ao mesmo tempo do contexto no qual se inserem. (SOUZA, 2003; SOUZA \& ARICA, 2006).

Nesse contexto, o entendimento da dinâmica competitiva em Arranjos Produtivos Locais (APLs) é fundamental para o estabelecimento de estratégias competitivas precisas, a superação de barreiras comerciais, a preservação de condições socioambientais satisfatórias e o direcionamento de novos investimentos.

Porém, por razões metodológicas, tradicionalmente as políticas de incentivo e os programas de apoio ao desenvolvimento e à competitividade industrial são distribuídos de forma genérica a regiões ou a setores, tratando aglomerados e segmentos produtivos como um bloco homogêneo e integral. Dessa forma, as diversidades internas dos arranjos locais e a estratificação entre empresas não são captadas, tornando tais iniciativas pouco eficientes e, muitas vezes, ineficazes (SOUZA \& ARICA, 2001).

\section{entendimento da dinâmica competitiva em APL's é fundamental para o estabelecimento de estratégias competitivas precisas.}

Um dos efeitos desse tratamento às aglomerações de atividades econômicas locais é que muitas empresas não conseguem se habilitar aos programas governamentais de apoio à competitividade. Estas acabam perdendo mercado e, em último caso, fechando. Para outras, tais iniciativas não satisfazem suas necessidades ou não contribuem para que elas superem suas barreiras organizacionais e tecnológicas.

A partir de uma perspectiva evolucionária, propõese neste artigo uma abordagem para o estudo da dinâmica competitiva de empresas em APLs. Inicialmente, são revistos alguns enfoques para o problema da estratificação de atividades tecnológicas. Em seguida, formula-se uma metodologia para o estudo da estratificação competitiva de empresas em APLs, tomando-se por analogia o conceito de "trajetória tecnológica". Logo após, apresenta-se um esboço de sua aplicação ao caso de um APL típico de regiões periféricas. Considerações finais sobre a abordagem e sua aplicação encerram o artigo. 


\section{ESTRATIFICAĈ̣̃O TECNOLÓGICA}

O entendimento de fatores endógenos e exógenos, de mercado, que condicionam o comportamento das empresas avançou bastante nos últimos anos (SOUZA \& ARICA, 2002). Entretanto, ainda permanece aberta a questão dos relacionamentos entre os fatores internos e externos da organização que emulam sua capacidade, competências, estratégias e comportamento em vários setores e arranjos industriais (ver, por exemplo, ALBINO et al., 1999; BRAGLIA \& PETRONI, 2000).

A partir de uma visão evolucionária dos processos de mudanças e inovação de longo prazo, Fujimoto (2001) propôs uma tipologia original para classificação das atividades, rotinas e padrões organizacionais de empresas. Nesse caso, o foco central da análise é nas trajetórias de processos de inovação de grande escala, que criam novos sistemas de manufatura competitivos entre si (como os sistemas Ford e Toyota de produção). Tal proposta inclui uma análise baseada em conjuntos de rotinas organizacionais e padrões técnicos previamente definidos, para a qual o autor propõe o conceito de "sistemas emergentes de multitrajetórias".

Entre os princípios evolucionários considerados nessa abordagem estão: (i) retenção - conceito associado à idéia de rotinas, conhecimento tácito e informações retidas ou apropriadas por grupos ligados diretamente à execução de certas tarefas; (ii) variação - conceito vinculado ao princípio lamarckiano de adaptação de certas rotinas através de feedbacks com o ambiente, mesmo que imperfeitamente; e (iii) seleção - conceito vinculado ao fato de que empresas com baixa performance podem ser eliminadas da competição pelos mercados, considerando, entretanto, que estas, sendo pressionadas a se aperfeiçoar e a mudar suas rotinas ao longo do tempo, conseguem prolongar seu ciclo de vida.

A tipologia de Fujimoto (op.cit.) divide as classes de rotinas e capacidade organizacionais em três diferentes níveis (ver Quadro 1):

Adicionalmente, como "capacidades auxiliares", o autor indica que devem ser avaliados padrões que caracterizem as atividades organizacionais mais básicas, como a identificação de problemas, suas soluções, e a retenção (aprendizagem e aplicação) das soluções obtidas. O que implica na necessidade do estudo dos padrões técnicos e das rotinas organizacionais.

Como verificado por Abramovitz (1986), através da análise do crescimento da taxa de produtividade em diversos países, um fenômeno que ocorre em ambientes econômicos competitivos é a estratificação em grupos pela capacidade de inovação. Assumindo um ambiente evolutivo, onde as firmas nascem, crescem e morrem, tal autor propôs uma classificação de países de acordo com sua capacidade de desenvolver e se apropriar de conhecimentos científicos e inovar tecnologicamente. A partir de um estudo em diversos países foi verificado que as taxas de crescimento da produtividade entre países industrializados tendiam a variar inversamente com os níveis de produtividade. Ou seja, aqueles de menor produtividade tendiam a ter uma taxa de crescimento da produtividade maior que os que apresentavam produtividade maior. Tal classificação divide os países em três grandes grupos, de acordo com seu domínio e postura tecnológica, respectivamente, os inovadores, os imitadores (ou seguidores) e "os que ficam para trás". Ou, como na denominação original: forging ahead, catching-up e falling behind, respectivamente. Esta abordagem, bem difundida na literatura sobre inovação e progresso técnico, é geralmente referida como "perspectiva catchingup". Utilizando essa mesma abordagem, Cimoli (1998), em um interessante trabalho, propõe uma vinculação dessa perspectiva com a estrutura e dinâmica dos Sistemas Nacionais de Inovação correspondentes.

Souza \& Arica (2001) propuseram adotar a perspectiva catching-up para o estudo e análise do processo competitivo de aglomerados e arranjos produtivos locais através de uma abordagem evolucionária. Nesse sentido, as empresas em arranjos produtivos locais podem ser classificadas em três grupos distintos:

Grupo 1 (Forging ahead) - compreende aquelas em-

Quadro 1: Estratificação de rotinas e capacidades organizacionais (FUJIMOTO, 2001).

\begin{tabular}{|l|l|}
\hline \multicolumn{1}{|c|}{ CLASSES } & \multicolumn{1}{c|}{ CARACTERÍTICAS } \\
\hline $\begin{array}{l}\text { 1.Capacidade de } \\
\text { manufatura rotinizada }\end{array}$ & $\begin{array}{l}\text { um conjunto de rotinas organizacionais que afetam o desempenho competitivo em } \\
\text { uma determinada posição; }\end{array}$ \\
\hline $\begin{array}{l}\text { 2. Capacidade de } \\
\text { aprendizagem rotinizada }\end{array}$ & $\begin{array}{l}\text { um conjunto de rotinas organizacionais que afetam o ritmo das melhorias contínuas, } \\
\text { bem como assimilação rápida em momentos críticos e a recuperação do ritmo normal; }\end{array}$ \\
\hline $\begin{array}{l}\text { 3. Capacidade de } \\
\text { aprendizagem evolucionária }\end{array}$ & $\begin{array}{l}\text { habilidades e capacidades não rotinizadas que afetam o desempenho das outras } \\
\text { capacidades. }\end{array}$ \\
\hline
\end{tabular}


presas que "pulam na frente" do processo competitivo do respectivo arranjo. Dominam o processo produtivo em termos técnicos, de custo, de qualidade e flexibilidade dos produtos. Estas empresas desenvolvem conhecimentos específicos e geram, a partir destes, produtos tecnológicos inovadores; competem externamente ao arranjo ou imitam, adaptam e assimilam tecnologia externa e desenvolvem soluções próprias. Despontam no cenário competitivo setorial/regional, ampliam mercados e dispõem de vantagens competitivas baseadas em competências específicas.

Grupo 2 (Catching-up) - caracterizado pelas empresas que buscam acompanhar o processo evolutivo tecnológico e organizacional das líderes (grupo 1), porém com uma certa defasagem técnica e organizacional. Não dominam conhecimento técnico, ou dominam, mas não têm capacidade de convertê-lo em tecnologia útil e desempenho operacional competitivo. Estas buscam adaptar e desenvolver produtos substitutos através de engenharia reversa e imitações simples. No decorrer do tempo, por restrições de competência interna, e investimentos em Pesquisa e Desenvolvimento (P\&D), gestão da produção e qualidade, somente uma pequena parcela destas consegue inclusão no grupo de liderança do arranjo.

Grupo 3 (Falling Back) - Este grupo caracteriza empresas que não conseguem acompanhar o avanço tecnológico e as exigências do mercado, competem principalmente pelo preço, tendem a se tornar cada vez mais defasadas tecnologicamente e a "desaparecer" da arena competitiva ou a perder a parcela mais significativa do seu mercado. Seguindo nessa trajetória, tais empresas estariam fadadas a pagar um preço cada vez mais alto por isso, devido ao fato de se tornarem meros clientes de produtos tecnológicos externos. Este grupo acaba se dedicando a nichos de mercado de baixo poder aquisitivo com processos produtivos baseados em tecnologias com demanda decrescente ou já em fase de obsolescência.

\section{ANÁLISE DA TRAJETÓRIA COMPETITIVA EM ARRANJOS PRODUTIVOS LOCAIS (APLS)}

O processo de estratificação de empresas em APLs pode ser entendido como reflexo do ambiente competitivo econômico, que surge a partir da diversidade de comportamentos e de diferentes estratégias competitivas frente a um mercado seletivo. A capacidade das empresas em adotar certos padrões técnicos, procedimentos e rotinas operacionais, característicos de cada setor/ambiente, sofre influências, por um lado, da tradição e da cultura local, e por outro, das demandas específicas do mercado, em termos de qualidade, diversidade e preço de cada produto, entre outras. Esta dinâmica forma o que se pode denominar de "trajetória competitiva" (SOUZA, 2003; SOUZA \& ARICA, 2003; SOUZA \& ARICA, 2005). Tal fenômeno pode ser analisado em termos de nichos de mercado, tecnologias, estratégias e rotinas, as quais caracterizam e definem uma "trajetória competitiva" específica de cada APL. A abordagem adotada baseia-se na análise da competitividade em arranjos produtivos locais a partir de uma aplicação adaptada dos conceitos de "trajetória tecnológica", "regimes tecnológicos" e "padrões técnicos" (NELSON \& WINTER, 1982; DOSI, 1988; VAN DE POEL, 2002) e de "estratificação competitiva" (SOUZA, 2003). Por tal abordagem, o foco da análise passa para a dinâmica competitiva das empresas em um determinado APL e, por conseqüência, em seus respectivos comportamentos frente às mudanças econômicas, sociais, ambientais, mercadológicas e tecnológicas, ao invés de se concentrar na evolução de uma tecnologia específica em termos globais, como o conceito tradicional de "trajetória tecnológica" sugere (CARLSSOM, 1997). O ponto de vista passa da "análise da evolução tecnológica" em si, para centrar-se em "como as firmas se comportam frente a essa evolução". Dessa forma, pode-se caracterizar a trajetória competitiva das empresas de um determinado APL frente às mudanças tecnológicas para avaliar quais os efeitos em termos da competitividade relativa no arranjo (SOUZA \& ARICA, 2005). A seguir, apresenta-se o esboço de um caso aplicado baseado em tal abordagem.

\section{Análise da Mudança Tecnológica em APLs: o caso da Cerâmica Vermelha do Norte Fluminense}

\section{Considerações gerais}

Os dois principais pólos da atividade de manufatura de cerâmica vermelha no Estado do Rio de Janeiro são os aglomerados de Campos e de Itaboraí-Manilha. Um terceiro aglomerado, com grande crescimento nos últimos anos, encontra-se no município de Três Rios.

O pólo da baixada campista, em termos da economia local, responde por aproximadamente $5 \%$ dos postos de trabalho da população economicamente ativa do município, o que representa algo em torno de 5.000 empregos diretos, distribuídos nas cerca de 110 cerâmicas do setor. Além da relevância em termos da economia local, associada ao segmento, há uma forte conotação social e ambiental vinculada à atividade, devido às precárias condições de trabalho e ao impacto ambiental provocado (SILVESTRE, 2001).

Quanto à educação formal, a grande maioria dos trabalhadores do setor não consegue ocupação em atividades mais dinâmicas, como o comércio varejista local. Muitos deles são provenientes do setor de cana-de-açúcar, quan- 
do dos períodos de entressafra. Neste sentido, o setor funciona como uma "válvula de escape" do setor sucroalcooleiro local, contribuindo para regular o quadro de mobilidade da mão-de-obra regional.

No aspecto ambiental, o desenvolvimento de programas de recuperação e de zoneamento de áreas de exploração é fundamental para garantir a sustentabilidade futura da atividade e das comunidades locais. Por outro lado, a escolha do aglomerado de cerâmica vermelha de Campos para este estudo justifica-se, em primeiro lugar, pelo fato de este segmento da atividade econômica local apresentar características similares às da maioria dos arranjos não-intensivos em tecnologia de microrregiões periféricas do Brasil, entre as quais, podem-se destacar: a baixa produtividade, mão-de-obra pouco qualificada, produtos de baixo valor agregado e processos produtivos rudimentares (SOUZA, 2003).

versos setores industriais, grosso modo, representam uma fonte exógena de mudança tecnológica. Porém, a viabilização da sua implementação envolve diversos fatores endógenos, como a estrutura organizacional, a eficiência do processo, a logística, o padrão de concorrência, a estrutura de custos e as competências.

O processo tradicional de queima a lenha está baseado em um modelo de processo produtivo cuja estrutura de custos e cadeia de valor específica, apesar de fundamentais do ponto de vista do padrão da competição local, mostram-se saturadas do ponto de vista tecnológico e de novos mercados. Nesse caso, a tecnologia utilizada impossibilita a diversificação de produtos (como telhas e revestimentos) devido a limitações inerentes ao processo de queima a lenha (por exemplo, quanto à temperatura e uniformidade). Tais restrições técnicas condicionam outros fatores que influenciam as estratégias e o desempenho competitivo das empresas, como o mix de produtos, a qualidade, a diferenciação e a exploração de novos mercados, entre outros.

Uma característica específica do segmento é que o mercado para tijolos e blocos cerâmicos não é exigente quanto à uniformidade, resistência, textura e outros atributos aparentes, pois acabará encoberto.

A escolha do arranjo de cerâmica vermelha de CamposRJ é paradigmática. Devido a suas características quase artesanais, em termos tecnológicos o aglomerado pode ser visto como um "enclave" de atraso tecnológico. Este seria como um "pior caso", para se observar e verificar aspectos da dinâmica evolucionária em arranjos locais. Com isso, acredita-se que, inclusive adicionalmente, possam surgir contribuições conceituais para a abordagem de microssistemas evolucionários "quase-estáticos".

De uma forma geral, excetuando algumas características dinâmicas, poder-se-ia afirmar que este segmento encontra-se em um ciclo vicioso, determinado, basicamente, pela competição pelo preço, pela incapacidade de incorporar tecnologias mais avançadas e pela dificuldade de explorar novos mercados.

Porém, algumas "janelas de oportunidade" podem ser vislumbradas, já exploradas em pólos ceramistas de outras regiões, como o de cerâmica estrutural em Itu e região (São Paulo), e os de cerâmica de revestimento em Seto (Japão) (IZUCHI, 1997), Sassuolo (Itália), Castellón (Espanha), Criciúma e Blumenau (Santa Catarina) (MEYER-STAMER et al., 2001).

A disponibilidade do gás natural na região Norte Fluminense, e da respectiva tecnologia para sua utilização como combustível nos processos produtivos de di-
Neste mercado, a concorrência pelo preço é especialmente predatória. Como o processo não possui muitas etapas de transformação (compreende basicamente extração, corte, moldagem, secagem e queima), não há margens suficientes para diluição dos custos, assim, qualquer elevação nos custos é, inexoravelmente, repassada aos preços.

Contudo, a mudança tecnológica envolvida na implementação da queima a gás natural não pode ser analisada somente pelo ponto de vista dos custos, pois esta possibilitará a transformação de toda, ou de grande parte da cadeia de valor e da configuração organizacional da indústria local. Se por um lado esta mudança eleva os custos do processo produtivo, e comparativamente seria hoje "menos lucrativa" em relação à lenha, por outro, permitiria outra carteira de produtos, com novas margens de lucros e a abertura de novos mercados. Neste sentido, a implementação do gás natural no segmento de cerâmica vermelha na região Norte Fluminense, por exemplo, não deve ser vista com base na estrutura produtiva atual (com o insumo lenha), o que certamente se revelará inviável economicamente para muitas unidades. Ela deve levar em consideração a tendência da trajetória competitiva do arranjo, a dinâmica dos mercados consumidores, dos novos produtos e dos substitutos. 
A princípio, através da mudança do processo produtivo e dos produtos, os fatores para viabilizar a implementação do gás dependeriam mais de elementos internos (maior controle sobre o processo, aumento da eficiência, redução do desperdício de matéria-prima, novos produtos, novos mercados, entre outros), do que externos (como políticas públicas de incentivos). Porém, do ponto de vista do desenvolvimento socioeconômico local, em um período de transição e adaptação, uma concentração maior de esforços pode ser fundamental para superar barreiras históricas dos efeitos de dependência da trajetória e o ciclo vicioso em que se encontra a indústria. Neste caso, incentivos específicos a certos grupos (admitindo-se uma estratificação) podem representar um fator fundamental para encorajar e impulsionar à mudança e possibilitar um salto tecnológico e de qualidade na indústria, considerando as diversidades do meio.

No caso específico do arranjo estudado, a utilização em maior escala do gás natural é reforçada pelo fato de a Bacia Petrolífera de Campos ser responsável atualmente por algo em torno de $40 \%$ da produção dessa fonte energética (SILVESTRE, 2001). De acordo com o Sindicato dos Ceramistas local, aproximadamente 20\% das empresas já contam com fornos instalados para a queima do combustível, através de convênio entre a Secretaria Estadual de Energia e a companhia local de gás (porém, durante a pesquisa verificou-se que algumas unidades ainda queimam lenha em fornos alternativos ou de forma sazonal). Um dos fatores que impedem uma maior adesão ao uso do gás é a indefinição com relação à política de preços para o combustível, que sofre efeitos da variação cambial em relação ao dólar, tornando os custos do seu consumo excessivamente altos quando comparados aos da lenha, apesar desta diferença já ter sido maior. Segundo alguns proprietários do ramo, um outro fator é o alto custo do investimento inicial necessário para implantação do sistema (em torno de R \$ 160.000,00).

Análises preliminares sobre a dinâmica competitiva do pólo local indicam que as diferentes estratégias competitivas das empresas do arranjo são fortemente condicionadas pela tecnologia adotada no processo de queima (SOUZA, 2003).

Nesse sentido, surgem algumas questões importantes: O processo de mudança tecnológica causa uma estratificação em grupos entre as empresas do arranjo? Quais os fatores que condicionam tal estratificação? Quais as principais características de cada grupo? Que tipo de barreiras impedem o avanço de cada grupo? Quais as alternativas para superá-las? Que tipo de apoio ou incentivo seria mais indicado a cada grupo? De modo a contribuir com algumas respostas a esses questionamentos, a seguir, apresenta-se uma metodologia adotada para a análise da mudança tecnológica e seus efeitos na dinâmica competitiva do Pólo de Cerâmica Vermelha de Campos, a qual, posteriormente, pretende-se estender a outros arranjos produtivos com características similares.

\section{Metodologia de pesquisa}

A abordagem proposta foi empregada em uma pesquisa de campo no pólo de cerâmica vermelha do Norte Fluminense (SOUZA, 2003; SOUZA et al., 2003). A seguir, apresenta-se uma síntese do trabalho realizado.

Inicialmente, uma amostra representativa do arranjo foi selecionada. O impacto da mudança tecnológica provocada pela implementação do gás natural, em comparação à queima a lenha, foi avaliado através da identificação e análise dos padrões técnicos de ambas as tecnologias, considerando-se também um sistema híbrido, de transição de uma para outra tecnologia. Através de uma variável referencial, a tecnologia, conceitualmente considerada como "uma forma de fazer as coisas", foi estabelecida uma taxonomia do "nível tecnológico", a partir das diferenças nos padrões técnicos identificados nos regimes tecnológicos verificados no sistema produtivo (basicamente: 1- queima a lenha, 2- queima mista, 3queima a gás).

Aqui, diferentes regimes tecnológicos $\left(\mathrm{RT}_{\mathrm{i}}, i=1, \ldots, n\right)$ representam segmentos nas trajetórias tecnológicas consideradas. No caso: $n=3, \mathrm{RT}_{1}=$ [lenha], $\mathrm{RT}_{2}=$ [regime misto] e $\mathrm{RT}_{3}=$ [gás]. Assume-se que cada regime é composto por $m$ padrões técnicos e organizacionais, os quais são estabelecidos no processo de aprendizagem e absorção tecnológica, específicos de cada unidade. $\mathrm{Na}$ passagem de um padrão técnico a outro, em cada regime, consideram-se "períodos estacionários" que representam lapsos temporais, certos vácuos, necessários à superação de barreiras endógenas, como ineficiência ou incapacidade própria, e exógenas, tais como desequilíbrios de preços relativos, políticas industriais desfavoráveis e crises econômicas e sociais (SOUZA, 2003; SOUZA \& ARICA, 2005).

\section{Metodologia de abordagem}

Para a realização do trabalho de campo, em um primeiro momento, buscaram-se informações e dados publicados a respeito de pólos similares de outras regiões, de forma a se definir que tipo e quais as informações a serem levantadas. Em seguida, este mesmo procedimento foi realizado para o pólo local. Constatou-se a existência apenas de informações genéricas sobre o pólo e a atividade, como os tipos de produtos fabricados, preços e as etapas do processo de produção. Tais informações serviram para um mapeamento geral das empresas do Pólo e do tipo de informação não disponível sobre elas. Dessa 
forma, foi definido um conjunto de informações a serem levantadas através de pesquisa direta.

A seguir foram coletados dados e informações de uma amostra estratificada com elementos representativos de cada um dos regimes considerados $\left(\mathrm{RT}_{1}, \mathrm{RT}_{2}\right.$, $\mathrm{RT}_{3}$ ). Assume-se que cada um desses regimes representa um estágio de desenvolvimento tecnológico no tempo, embora eles coexistam na prática. Cada regime característicos, os quais devem ser assimilados na transição entre dois regimes tecnológicos diferentes (SOUZA, 2003). Os padrões técnicos e organizacionais, que caracterizam cada um desses regimes, foram levantados através de uma auditoria da manufatura (ver SOUZA et al., 2003).

A etapa seguinte compreendeu um levantamento de informações e dados primários através de entrevistas técnicas e observações in loco em uma amostra estratificada das empresas do referido Pólo. Para tanto, foi elaborado previamente um questionário para o levantamento de uma amostra representativa da diversidade tecnológica do pólo. Foram consultados profissionais e pesquisadores de instituições da região nessa área, entre os quais: o Sindicato dos Ceramistas, os Laboratórios de Materiais Avançados e de Engenharia Civil (ambos da UENF), além de técnicos do Parque de Alta Tecnologia do Norte Fluminense (TECNORTE), do Centro Federal de Ensino Tecnológico (CEFET-Campos), do Serviço Nacional de Aprendizagem Industrial (SENAI) local e dirigentes dos próprios ceramistas. compreende certos padrões técnicos e organizacionais

três escolhidas de forma aleatória entre aquelas citadas. $\mathrm{Na}$ amostra estratificada as empresas selecionadas para o primeiro grupo corresponderam a praticamante $100 \%$ do seu estrato na população. As do segundo grupo, a cerca de $80 \%$. O terceiro grupo, apesar de a amostra para esse segmento ser baixa em relação ao seu correspondente populacional $( \pm 5 \%)$, verificou-se através de um mapeamento prévio e visitas informais a uma dezena de outras unidades aleatórias, a inexistência de diversidade tecnológica que justificasse adicionar outras unidades. Considerando que a população total do arranjo é de aproximadamente 110 unidades, pode-se considerar a amostra estratificada das 15 unidades selecionadas como altamente representativa.

\section{Metodologia de procedimento (pesquisa de campo)}

Essa etapa do trabalho, a pesquisa de campo propriamente dita, compreendeu duas fases: uma, (i) de entrevistas com o proprietário ou gerente da empresa; e outra, (ii) de acompanhamento do processo produtivo. Na primeira fase, o proprietário (ou gerente) respondeu a um questionário-padrão, com informações gerais sobre a empresa, dados relacionados a administração, produtos, mercado, investimentos e estratégias. $\mathrm{Na}$ segunda fase, fez-se um acompanhamento in loco de todas as etapas do processo produtivo em cada empresa, desde a extração nas jazidas, passando pelas etapas de preparação da massa e fabricação, até o estoque do produto acabado, com ênfase nos pontos diferenciais, com o preenchimento de um segundo questionário-padrão. Além das observações das etapas do processo, cada ponto representativo de diversidade em termos de equipamento, método ou rotinas, foi fotografado. Com tais informações, elaborou-se um Relatório Preliminar, com uma análise empresa por empresa, etapa por etapa.

\section{Análise dos dados e informações}

Para se preservar o sigilo das informações coletadas, os verdadeiros nomes das empresas são omitidos, adotando-se uma notação alfabética para denominar cada empresa avaliada, da seguinte forma: Cerâmica A, Cerâmica B, e

Os entrevistados responderam a pergunta de quais empresas eles enquadrariam em cada um dos três grupos propostos, adotando como parâmetro o tripé tecnologia $\mathrm{x}$ produto x mercado. Sugeriu-se que baseassem suas escolhas em critérios como (i) modernização do processo produtivo, (ii) produtos de melhor qualidade e (iii) agregação de valor. Após as indicações, foram identificadas as empresas mais citadas, em cada um dos grupos previamente definidos. O total de empresas selecionadas foi de quinze (15) ao todo, sendo quatro em cada grupo, e outras assim por diante, até a Cerâmica O (15 empresas).

A maioria das empresas visitadas possui trabalhadores provenientes da indústria da cana-de-açúcar, devido à redução do número de postos de trabalho nesse setor local nos últimos anos. Tal mão-de-obra é pouco qualificada e carente de formação técnica, com expressiva taxa de analfabetismo, o que compromete iniciativas de melhoria da qualidade no processo de fabricação das cerâcaracterística peculiar a administração familiar. micas. Além disso, a maioria das empresas possui como 
Das 15 cerâmicas visitadas, apenas oito empresas (A, B, D, G, H, K, L, M) utilizavam efetivamente o gás natural como combustível. Essas empresas estão entre as que têm maior capacidade de queima e produzem maior volume de peças por mês. Devido ao padrão mais homogêneo proporcionado por esse combustível, os produtos fabricados pelas unidades desse grupo apresentam características mais uniformes e de melhor qualidade.

A Cerâmica A, produtora de blocos cerâmicos (tijolos), é uma das três empresas que implantaram no processo de fabricação etapas seqüenciais semi-automatizadas (as outras, são a C e a L). Neste caso, a interferência humana acontece somente na etapa do abastecimento do caixão dosador e na parte do transporte das peças do secador para os fornos.

A Cerâmica L tem como principal produto telhas revestidas (Foto 1). Tal produto passa por um processo de tratamento de impermeabilidade que aumenta a durabilidade e a resistência do material. A empresa chega a oferecer uma garantia da qualidade de dez anos para esses produtos. Além disso, a empresa introduziu no processo um equipamento para resfriamento da água antes da extrusão (maromba), o que, segundo o gerente operacional, deixa a massa mais "solta", reduzindo a freqüência de interrupções do processo produtivo para limpeza do equipamento, além de proporcionar melhor textura das peças. Segundo o proprietário, a empresa L é uma das três no Brasil (as outras com sede em Santa Catarina e São Paulo) a empregar tal tecnologia na fabricação de telhas. Essa tecnologia tem patente detida pela Universidade Federal do Rio Grande do Sul (UFRGS), que recebe royalties da empresa. Pelos dados analisados verifica-se que a empresa consegue um maior valor agregado nas peças fabricadas, com uma diferença no preço do milheiro que pode dobrar em relação ao preço das produzidas tradicionalmente (telhas naturais). Vale lembrar

\section{Foto 1: Telhas revestidas (Cerâmica L).}

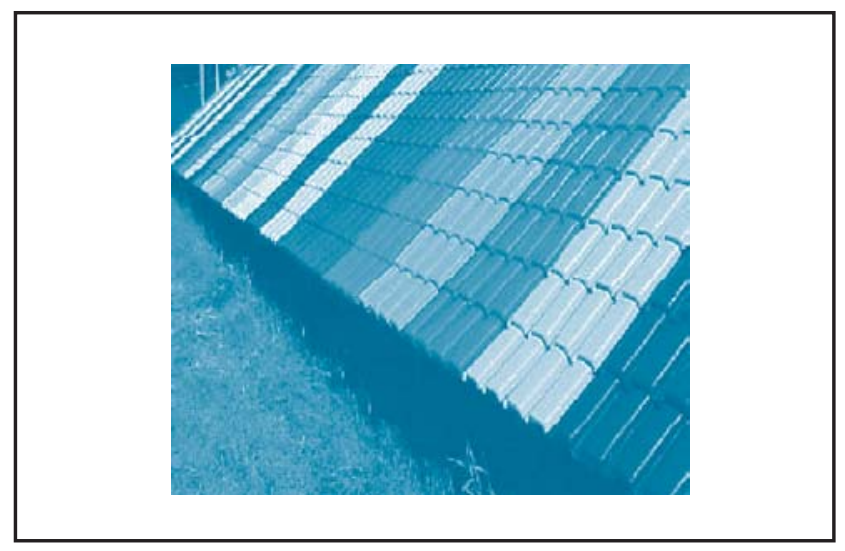

que o uso de tecnologia patenteada é um caso atípico para as empresas estudadas. Um dos pontos mais interessantes observados em seu processo produtivo é a utilização de um cortador mecânico (sem fios de corte), no qual um tipo de pá faz o corte na massa, sendo acionado pelo próprio movimento da massa após a extrusão (ver Foto 2), o que torna o processo mais eficiente.

Nos cortadores convencionais (automáticos) o corte é realizado por fios metálicos (arames), que constantemente se partem devido ao desgaste, ocasionando paradas não programadas e perdas no processo. Esta "inovação" reduziu substancialmente o número de paradas no processo com o conseqüente aumento da produtividade do trabalho.

Outras empresas, como as Cerâmicas B, E, K e a própria Cerâmica L, também têm como diferencial o tratamento pós-extração da massa (argila). Essas empresas realizam um tratamento diferenciado nesta etapa do processo, devido à laminação dupla e à posterior estocagem em silos da massa trabalhada, com, inclusive, a utilização de testes em laboratórios credenciados. As Cerâmicas $\mathrm{C}$ e $\mathrm{F}$ investem em equipamentos modernos e na diversificação de produtos (Fotos 3 e 4, respectivamente). Segundo o proprietário da Cerâmica F, a reestruturação do seu setor administrativo fez com que a empresa tivesse uma melhor integração entre as partes da gestão e do processo produtivo, através de melhorias nas operações, o que aproximou os setores de administração da produção e de chão-de-fábrica.

As Cerâmicas F, I, J, N e O trabalham com uma composição da massa muito heterogênea (Foto 5, como exemplo) e não realizam tratamento pós-extração das argilas. Outra característica comum é a não utilização de termopares (sensores para o controle da temperatura interna dos fornos). Além disso, os equipamentos de produção são muito antigos, pouco eficientes e o layout
Foto 2: Cortador mecânico giratório (idem).




da planta e as instalações, em geral, são improvisadas (especialmente as elétricas). A não realização de inspeção em nenhuma das etapas do processo contribui para que a massa com resíduos orgânicos acentue as perdas totais no processo. Tais fatores comprometem a qualidade de seus produtos (Foto 6).

De acordo com a metodologia adotada, foram identificadas as seguintes características para cada grupo:

No primeiro grupo (Grupo 1), constituído por aquelas unidades consideradas as mais dinâmicas, encontram-se as cerâmicas que estão à frente do processo competitivo no arranjo. Dominam técnicas de produção que possibilitam uma melhor qualidade dos produtos e diversificação de peças. Tais empresas adquirem conhecimentos específicos através de congressos e revistas especializadas, utilizando-os de acordo com suas necessidades e restrições. Suas estratégias estão voltadas para a produção de itens de maior valor agregado e a ampliação do mercado em nichos específicos,

Foto 3: Prensas modernas para produção de telhas (Cerâmica C).

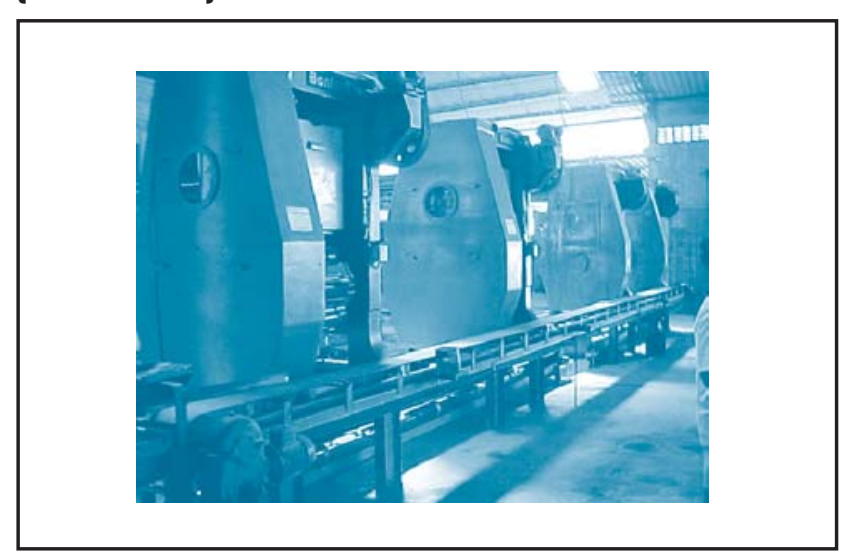

Foto 5: Massa heterogênea (Cerâmica 0).

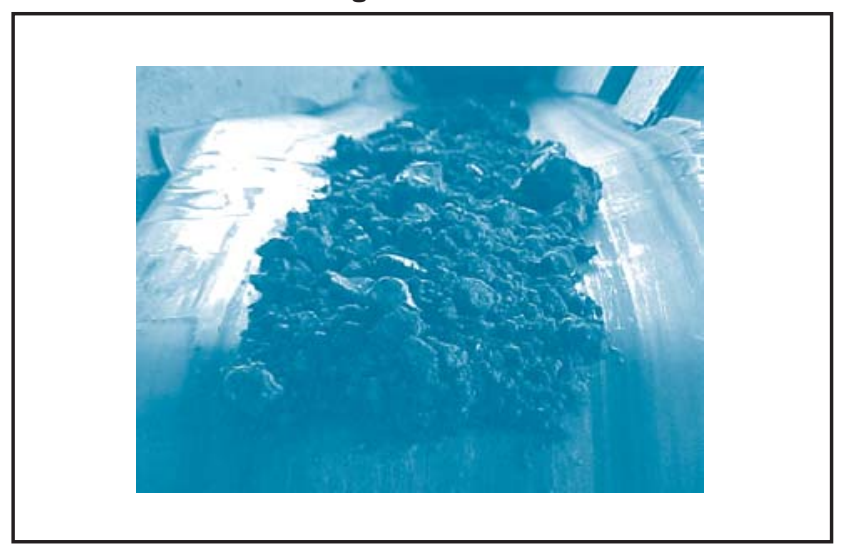

atendendo a uma parcela do mercado de maior poder aquisitivo e com demanda crescente. Este grupo representa aproximadamente $4 \%$ das empresas do pólo estudado.

Nas empresas do segundo grupo (Grupo 2), as intermediárias, estão as unidades que buscam acompanhar ou se integrar ao grupo líder, mas que ainda apresentam barreiras e limitações internas, tanto no processo produtivo quanto nas atividades de gestão da cadeia de valor que impedem um melhor desempenho. Apresentam deficiência com relação ao controle de custos do processo, e não utilizam técnicas de controle do processo produtivo, como conseqüência, suas margens de lucro são muito menores que as do Grupo 1. Apresentam estratégias de mercado desfocadas, tentando se posicionar para atender aos consumidores em geral, investindo na diversificação de produtos sem estabelecer nichos específicos. Este grupo representa em torno de $10 \%$ das empresas do arranjo.

Já no último grupo (Grupo 3), encontram-se aquelas

Foto 4: Bloco vazado aparente e plaquetas de revestimento (Cerâmica F).

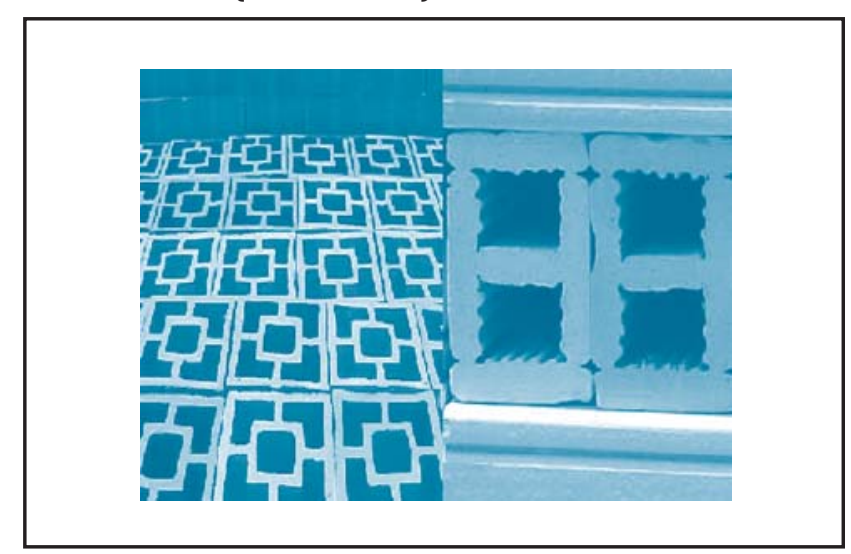

Foto 6: Blocos cerâmicos danificados (idem).

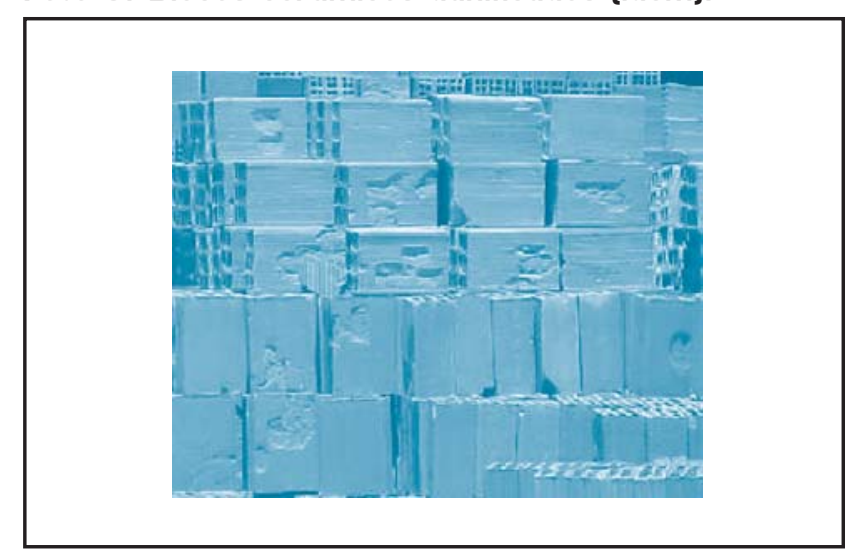


empresas caracterizadas por não conseguir acompanhar o processo competitivo nem introduzir mudanças tecnológicas. Estas, não conseguem nem mesmo se tornar "receptoras" de tecnologia externa (e.g., a implantação de queima a gás), tendendo a se tornar cada vez mais excluídas pelo processo competitivo. Tal grupo abrange empresas que atendem a uma grande parcela do mercado, porém, em condições de "concorrência predatória", sofrendo, como conseqüência, forte pressão sobre os preços. Contudo, ainda conseguem vender seus produtos para consumidores pouco exigentes, em nichos de baixo poder aquisitivo. Neste grupo se enquadram o restante das empresas do Pólo.

As Tabelas 1 e 2, a seguir, apresentam um resumo com as características verificadas em cada grupo. Na Tabela 1, são indicados (quando necessário) os valores menor e maior, respectivamente, encontrados para o parâmetro correspondente.

\section{Conclusões da pesquisa de campo}

Devido ao fato de atuarem em um mercado pouco restritivo quanto à qualidade, com forte pressão por menores preços, o que se observa é que, tanto as empresas do Grupo 1 (que detêm maior controle na especificação de seus produtos), quanto aquelas do segundo e terceiro grupos conseguem vender seus produtos por uma pequena variação de preços. Tal fato pode ser explicado por não haver regulamentação quanto às normas de qualidade e conformidade (normalização) para a maior parte dos produtos comercializados. Como resultado, tanto aquelas empresas que realizam testes (como, por exemplo, de absorção de água, resistência, conformidade nas dimensões e análise granulométrica da argila), quanto aquelas que não realizam nenhum tipo de ensaio competem entre si, porém com grande defasagem de custos operacionais e de qualidade dos produtos.

Deve-se levar em consideração que o gás natural, apesar de representar um forte condicionante na estratificação do arranjo, não pode ser considerado isoladamente. As estratégias de diversificação de produtos, redução de desperdícios e controle do processo são fatores determinantes do posicionamento competitivo das empresas no arranjo. Por exemplo, a cerâmica E, apesar de utilizar lenha como combustível, devido aos investimentos no controle do processo (principalmente na seleção de argilas e na temperatura de queima) e na exploração de mercados alternativos, de maior valor agregado (produtos rústicos), apresenta desempenho acima da média do seu grupo (2). Por outro lado, a grande maioria das empresas do Pólo (Grupo 3) apresenta claras deficiências técnicas e organizacionais. Apesar disso, estas ainda encontram mercado em nichos de baixa renda, especialmente nas favelas da cidade do Rio de Janeiro e áreas de periferia de municípios do Grande Rio, da Região dos Lagos e da região denominada de Baixada Campista.

Tabela 1: Características por grupo (SOUZA, 2003).

\begin{tabular}{|c|c|c|c|}
\hline PARÂMETRO & GRUPO 1 & GRUPO 2 & GRUPO 3 \\
\hline Início da produção & $1973-1997$ & $1961-1996$ & 1973-1993 \\
\hline Capacidade de produção & $540.000-1.500 .000$ & $1.200 .000-1.800 .000$ & $450.000-1.500 .000$ \\
\hline Tipo de forno & $\begin{array}{l}\text { túnel, hoffman, caieira, } \\
\text { câmara }\end{array}$ & $\begin{array}{l}\text { vagão, paulistinha, } \\
\text { hoffman, circular }\end{array}$ & circular, hoffman \\
\hline Combustível para queima & lenha* e gás & lenha*** e gás & lenha \\
\hline Tipo de secagem & natural/artificial & natural/artificial & natural \\
\hline Produtos fabricados & $\begin{array}{l}\text { tijolos, telhas naturais e } \\
\text { revestidas, tijolos } \\
\text { maciços. }\end{array}$ & $\begin{array}{l}\text { tijolos, plaquetas e telhas } \\
\text { naturais }\end{array}$ & tijolos \\
\hline 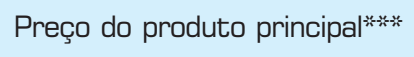 & $R \$ 115(T i)-R \$ 900(T r)$ & $R \$ 90(T i)-R \$ 300(T)$ & $\mathrm{R} \$ 95-\mathrm{R} \$ 100$ \\
\hline № de funcionários & $30-110$ & $35-54$ & $17-18$ \\
\hline Principais mercados & $\begin{array}{l}\text { RJ, Região dos Lagos, } \\
\text { Grande Rio }\end{array}$ & $\begin{array}{l}\text { RJ, Campos, Grande Rio, } \\
\text { Região dos Lagos, Volta } \\
\text { Redonda }\end{array}$ & $\begin{array}{l}\text { Grande Rio, RJ, Campos, } \\
\text { ES, Região dos Lagos }\end{array}$ \\
\hline
\end{tabular}




\section{CONSIDERAC̣̃̃ES FINAIS}

Indústrias, setores, cadeias produtivas, e até pequenos arranjos locais, compreendem empresas com graus diferenciados de recursos, competências e desempenho competitivo. Neste sentido, o levantamento da diversidade e a análise da estratificação em arranjos industriais tornam-se importantes tanto do ponto de vista da Organização Industrial como para a priorização e direcionamento de estratégias, ações, programas e políticas industriais de desenvolvimento econômico-social e ambiental e de aumento da competitividade local.

Através da abordagem adotada neste trabalho, puderam ser estabelecidos vínculos entre os fatores de mudança tecnológica, seus efeitos na dinâmica competitiva do arranjo e o processo de estratificação em grupos. Foram identificadas características particulares que afetam o desempenho das empresas de cada grupo em termos do processo, produto e mercado.

A confirmação da existência de grupos de empresas em diferentes estágios e padrões competitivos evidencia a necessidade de que programas de apoio e incentivos ao APL incluam estratégias de benchmarking e up-grading tecnológico considerando tal diversidade. Apesar da definição de tais estratégias extrapolar o escopo deste tra- balho, preliminarmente, podem-se fazer algumas considerações para dinamização do pólo analisado conforme as características de cada grupo:

Grupo 1 - investimentos em projetos de produtos cerâmicos de maior valor agregado, otimização do processo produtivo, além de ações no sentido de garantir o fornecimento de longo prazo do gás natural. Ressalta-se também a necessidade da implantação de um programa de melhoria da qualidade e certificação de produtos segundo as normas técnicas vigentes, para que tais empresas possam ter acesso a mercados externos em condições similares às dos concorrentes.

Grupo 2 - a abertura de linhas de financiamento para modernização da planta industrial, especialmente para a construção de fornos mais eficientes e capacitação dos operadores para queima a gás, convênios com instituições de ensino para treinamento na área de instrumentação, análise de custos da produção e gestão de operações. Tais condições facilitariam o processo de transição para padrões do grupo líder.

Grupo 3 - que compreende mais de $90 \%$ das unidades, iniciativas no sentido de desburocratizar a concessão de licenças ambientais e o incentivo à formalização da empresa privilegiariam aquelas mais bem administradas e capacitadas.

Tabela 2: Resumo da estratificação competitiva para o pólo de cerâmica vermenha do Norte Fluminense (SOUZA, 2003).

\begin{tabular}{|c|c|c|c|c|}
\hline \multirow[t]{2}{*}{ ESTRATIFICAÇÃO } & \multirow[t]{2}{*}{ CERAMMIGAS } & \multicolumn{3}{|c|}{ PRINCIPAIS CARAGTERÍSTICAS } \\
\hline & & PROCESSO & PRODUTO & MERGADO \\
\hline Grupo 1 & $B, L$ & $\begin{array}{l}\text { Unidades mais compactas; } \\
\text { Maior produtividade; Queima } \\
\text { mais eficiente; Realização de } \\
\text { testes nas argilas; } \\
\text { Tratamento pós-extração; } \\
\text { Reaproveitamento do calor } \\
\text { dos fornos para secagem. }\end{array}$ & $\begin{array}{l}\text { Realização de } \\
\text { ensaios de } \\
\text { conformidade; } \\
\text { Maior qualidade; } \\
\text { Diversificação } \\
\text { direcionada. }\end{array}$ & $\begin{array}{l}\text { Exploração de } \\
\text { nichos específicos; } \\
\text { Mercado de maior } \\
\text { poder aquisitivo. }\end{array}$ \\
\hline Grupo 2 & $\begin{array}{l}A, C, D, E \\
F, G, K, M\end{array}$ & $\begin{array}{l}\text { Investimentos na } \\
\text { modernização dos fornos; } \\
\text { Substituição (lenta) da lenha } \\
\text { pelo gás; Iniciativas de } \\
\text { redução dos custos. }\end{array}$ & $\begin{array}{l}\text { Testes informais } \\
\text { de conformidade; } \\
\text { Diversificação não } \\
\text { direcionada a } \\
\text { nichos específicos. }\end{array}$ & $\begin{array}{l}\text { Estratégias } \\
\text { indefinidas; } \\
\text { Não vende para } \\
\text { nichos específicos. }\end{array}$ \\
\hline Grupo 3 & $\mathrm{H}, \mathrm{I}, \mathrm{J}, \mathrm{N}, \mathrm{O}$ & $\begin{array}{l}\text { Administração familiar; } \\
\text { Fornos ineficientes; } \\
\text { Equipamentos rudimentares; } \\
\text { Baixa produtividade; } \\
\text { Desconhecimento das perdas } \\
\text { no processo e dos seus } \\
\text { custos. }\end{array}$ & $\begin{array}{l}\text { Não realização } \\
\text { de testes nem } \\
\text { inspeção; Peças } \\
\text { de baixa qualidade. }\end{array}$ & $\begin{array}{l}\text { Venda para } \\
\text { nichos de baixo } \\
\text { poder aquisitivo }\end{array}$ \\
\hline
\end{tabular}


Como conseqüência da aceleração do processo de transição bottom-up, a tendência é a redução das unidades com padrões do terceiro grupo. Entretanto, o ritmo e a intensidade desse processo dependerá das condições de mercado e das intervenções regulatórias no segmento. Por fim, algum tipo de governance de modo a incentivar a formalização de alianças e redes de empresas pode contribuir para o fortalecimento da competitividade do pólo local.

Nesse sentido, a abordagem proposta mostrou-se robusta para o entendimento da dinâmica competitiva no pólo estudado, captando a diversidade existente e os padrões característicos de cada grupo, com perspectivas promissoras de aplicação a outros arranjos produtivos locais.

\section{Artigo recebido em 08/04/2005 Aprovado para publicação em 24/11/2005}

\section{- Referências Bibliográficas}

ABRAMOVITZ, M. Catching up, forging ahead and falling behind. Journal of Economic History, v. 46, n. 2, p. 385-406, 1986

ALBINO, V. GARAVELLI A. \& SCHIUMA, $G$. Knowledge transfer and inter-firm relationships in industrial districts: the role of leader firm. Technovation, v. 19,1999, p. 53-63.

BRAGLIA, M. \& PETRONI, A. Towards taxonomy of search patterns of manufacturing flexibility in small and medium sized firms. Omega, v. 28, 2000, p. $195-213$

CARLSSON, B. (Ed.). Technological systems and industrial dynamics. Dordrecht: Kluwer Acad. Publ., 1997.

CHANDLER, J. R. A. D., HAGSTRÖM P. \& SÖLVELL, Ö The dynamic firm. Oxford: Oxford University Press, 1999.

CIMOLI, M. National system of innovation: a note on technological asymmetries and catching-up perspectives. International Institute for Applied Systems Analysis (IIASA). Interim Report IR-98030/June, 1998.

DOSI, G. Sources, procedures and microeconomics effects of innovation. Journal of Economic Literature, v. 26, 1988, p. 1120-71.

. Technological paradigms and technological trajectories, Research Policy, v. 11, 1982, p. 147-162.
FUJIMOTO, T. Multi-path system emergence - an evolutionary framework to analyze process innovation. Conference "The Future of Innovation Studies", Eindhoven University of Technology, The Netherlands, 20-23, September. 2001 .

IZUCHI, H. Conflict between two industrial networks: technological adaptation and inter-firm relationships in the ceramics industry in Seto, Japan. Regional Studies, v. 31, n. 2, 1992, p. 117-129.

KLIEMANN, F. J. \& HANSEN, P. B. A emergência da mesoanálise como forma de avaliação de cadeias produtivas e da competitividade empresarial sistêmica. Em: Anais do XXI Encontro Nacional de Engenharia de Produção (ENEGEP), PUC, CuritibaPR,23 a 25 outubro, 2002

MALECKI, E. J. \& ÖINAS, P. (Eds.) Making connections: technological learning and regional economic change. England: Ashgate, Aldershot, 1998.

MEYER-STAMER, J., MAGGI, C. \& SEIBEL, S. Cadeia de valor global do setor cerâmico, Institute of Development Studies - IDS, SussexUK, 2001. Disponível em <http:// www. meyer-stamer.de/portindex.html>. Acesso em: 12 de dez. 2005.
NELSON, R. R. \& WINTER, S. An evolutionary theory of economic change. Cambridge: Harvard Univ. Press, 1982.

PORTER, M. E. A vantagem competitiva das nações. Rio de Janeiro: Campus, va das
1989.

SILVESTRE, B. S. Uma análise competitiva do setor ceramista de Campos dos Goytacazes. Dissertação (Mestrado em Ciências de Engenharia), Universidade Estadual do Norte Fluminense, Campos, Rio de Janeiro, 2001.

SOUZA, S. D. C. Uma abordagem evolucionária da dinâmica competitiva em arranjos produtivos locais. Tese (Doutorado em Ciências de Engenharia, Eng. de Produção). Universidade Estadual do Norte Fluminense, Campos dos Goytacazes, Rio de Janeiro, 2003

\& ARICA, J. Estratificação Competitiva de Firmas em Setores Industriais: uma abordagem metodológica. Em: Anais do VIII Simpósio de Engenharia de Produção (SIMPEP), UNESP, Bauru, S.Paulo, 2001. Disponível em <http:// www.simpep.feb.unesp.br/ ana8c.html\#GE >. Acesso em: 12 de dez. 2005.
. Competitividade industrial e regional: medidas e dicotomias, Anais do XXII Encontro Nacional de Engenharia de Produção (ENEGEP), PUC, Curitiba, PR, Brasil, 22 a 25 de outubro, 2002.

. Análise da trajetória competitiva em um arranjo produtivo local. Em: Anais do XXIII Encontro Nacional de Engenharia de Produção (ENEGEP), IFOP, Ouro Preto-MG, 22 24, Outubro, 2003.

Estratificação tecnológica e rajetória competitiva em um arranjo produtivo local. Anais do XXV Encontro Nacional de Engenharia de Procontro Nacional de Engenharia de Pro-
dução (ENEGEP), PUC, Porto Alegre, RS, Brasil, 29 de outubro a 01 de novembro, 2005.

Uma análise comparativa entre Sistemas de Inovação e o Diamante de Porter na abordagem de arranjos produtivos locais. Produção, v. 16 n. 1, 2006.

\& ELER, D. Um estudo sobre o impacto da mudança tecnológica no pólo de cerâmica vermelha do Norte Fluminense. Em: Anais do XXIII Encontro Nacional de Engenharia de Produção (ENEGEP), IFOP, Ouro Preto-MG, 22-24, outubro, 2003.

van de POEL, I. On the role of outsiders in technical development. Technology Analysis \& Strategic Management, v. 12, n. 3,2000 , p. 383-398.

\section{- Sobre os autores}

\section{Sebastião Décio Coimbra de Souza}

Universidade Estadual do Norte Fluminense - UENF, Laboratório de Engenharia de Produção

Endereço: Av. Alberto Lamego, 2000 - CEP 28013-602

Telefone: (22) 2726-1632 ramal 210, Fax ramal 211

Email: decio@uenf.br

\section{José Arica}

Universidade Estadual do Norte Fluminense - UENF, Laboratório de Engenharia de Produção

Endereço: Av. Alberto Lamego, 2000 - CEP 28013-602

Telefone: (22) 27261632 ramal 210, Fax ramal 211

Email: arica@uenf.br 